\title{
Método de determinação e avaliação da depleção de oxitetraciclina em camarão marinho
}

\author{
Beatriz Regina Brito de Oliveira Lavorante(1), Paloma Nascimento dos Santos ${ }^{(2)}$, \\ Paula Tiyemi Shinozaki Mendes ${ }^{(3)}$ e Emiko Shinozaki Mendes ${ }^{(4)}$
}

\begin{abstract}
(1)Universidade Federal Rural de Pernambuco (UFRPE), Departamento de Pesca e Aquicultura, Avenida Dom Manuel de Medeiros, s/no, Dois Irmãos, CEP 51171-900 Recife, PE. E-mail: beatrizrbo@gmail.com ${ }^{(2)}$ Instituto de Tecnologia de Pernambuco, Avenida Professor Luís Freire, № 700, Cidade Universitária, CEP 50740-540 Recife, PE. E-mail: palominha.santos@gmail.com ${ }^{(3)}$ Universidade Federal de Pernambuco, Departamento de Estatística, Avenida Professor Moraes Rego, s/no, Cidade Universitária, CEP 50670-901 Recife, PE. E-mail: paulashinozaki@hotmail.com (4)UFRPE, Departamento de Medicina Veterinária. E-mail: esmendes@dmv.ufrpe.br
\end{abstract}

Resumo - O objetivo deste trabalho foi validar um método para determinação de resíduos de oxitetraciclina (OTC) em camarões, por meio de cromatografia líquida de alta eficiência, e avaliar, pelo método validado, a depleção de resíduos de OTC em camarões in vivo. Para a validação, foram utilizados camarões isentos de OTC e camarões adicionados de OTC in vitro. Foram estabelecidos: seletividade, tempo de retenção, linearidade (coeficiente de correlação), faixa de trabalho, recuperação relativa, limites de detecção e quantificação do método (LDM e LQM, respectivamente) e repetibilidade. Para o experimento in vivo, rações com 200, 400 e $500 \mu \mathrm{g} \mathrm{g}^{-1}$ de OTC foram administradas aos camarões durante 14 dias. Foi avaliada a concentração do resíduo desse antibiótico no músculo e na carapaça até 22 dias após a suspensão da droga. O coeficiente de correlação linear foi de 0,9997 para o extrato fortificado da matriz, na faixa de trabalho de 0,02 a $0,4 \mu \mathrm{g} \mathrm{g}^{-1}$; a recuperação foi de $106 \pm 17,1 \%$ e os LDM e LQM foram de 0,006 e $0,019 \mu \mathrm{g} \mathrm{g}^{-1}$, respectivamente. O tempo de residência da droga na carapaça dos animais (de 10 a 13 dias) foi maior em comparação ao tempo de residência no músculo (5 dias).

Termos para indexação: Litopenaeus vannamei, antibiótico, cromatografia líquida de alta eficiência, tempo de depleção.

\section{Method for the determination and evaluation of oxytetracycline depletion in marine shrimp}

\begin{abstract}
This work aimed at validating a method for the determination of oxytetracycline (OTC) residues in shrimp by means of high performance liquid chromatography (HPLC), and at evaluating the OTC residue depletion in shrimps in vivo using the validated method. The shrimp used for validation were either not submitted or submitted to in vitro OTC addition. Selectivity, retention time, linearity (correlation coefficient), work range, relative recovery, detection and method quantification limits and repeatability were determined. For the in vivo experiment, shrimp were fed with feed medicated with OTC at 200, 400 and $500 \mu \mathrm{g} \mathrm{g}^{-1}$ for 14 days. Oxytetracycline residue concentration in the animals' muscle and carapace was assessed for up to 22 days after stopping medication. The results obtained were: 0.9997 linear correlation coefficient for the fortified matrix extract within a work range of $0.02-0.4 \mu \mathrm{g} \mathrm{g}^{-1}, 106 \pm 17.1 \%$ recovery and 0.006 and $0.019 \mu \mathrm{g} \mathrm{g}^{-1}$ detection and quantification limits, respectively. A greater OTC residence time was observed in the carapace (10 to 13 days) when compared to the muscle ( 5 days).
\end{abstract}

Index terms: Litopenaeus vannamei, antibiotic, high performance liquid chromatography, depletion time.

\section{Introdução}

O cultivo comercial de camarões no Brasil tem quase 40 anos e seu crescimento foi favorecido pelo desenvolvimento de técnicas de cultivo e pela utilização de espécies mais adaptáveis, com destaque para Litopenaeus vannamei, originária do Oceano Pacífico e introduzida no Brasil na década de 1980 (Brasil, 2001).
A carcinicultura brasileira enfrentou recentemente situações adversas, causadas principalmente pelo surgimento e disseminação de doenças, que contribuíram para uma perda de $27,9 \%$ na produção entre os anos de 2003 e 2005 (Food and Agriculture Organization of the United Nations, 2008). A partir do ano de 2006, foi observada uma reação do setor, porém ainda em recuperação gradativa. 
As doenças que acometem os camarões podem ser causadas por vírus, bactérias, fungos, protozoários e outros organismos. Embora os vírus desempenhem o papel de agentes etiológicos primários responsáveis por grandes perdas nos cultivos, as bactérias se destacam por estar naturalmente presentes na água. Esses microrganismos têm papel significativo nos ciclos biogeoquímicos dos ambientes aquáticos e são potenciais causadores de bacterioses de etiologia primária ou secundária (Barbieri Júnior \& Ostrensky Neto, 2002). Entre as doenças de origem bacteriana, destacam-se aquelas causadas pelos gêneros Vibrio e Rickettsia, responsáveis pelas vibrioses e pela hepatopancreatite necrotizante (NHP), respectivamente. Ambas se instalam quando o animal está imunodeprimido (Lightner, 1996).

A administração de antimicrobianos visando prevenir ou eliminar as enfermidades na carcinicultura está bastante disseminada, e a oxitetraciclina (OTC) é um dos compostos de uso mais comum devido à eficiência contra bactérias gram-negativas e positivas e à baixa toxicidade (Oka et al., 2000; Lyle-Fritch et al., 2006; Uno et al., 2006). Com a incorporação de OTC nos tecidos dos animais medicados, os efeitos tóxicos da droga para os humanos podem incluir irritações gastrintestinais, pancreatite, diarreia, alterações no fígado e nos rins, escurecimento dos dentes e deposição nos ossos, porém raramente foi constatada anafilaxia (Brunton, 2006).

A OTC pode ser administrada em várias etapas do cultivo de camarões para o tratamento de vibrioses (Barbieri Júnior \& Ostrensky Neto, 2002) e apresenta uma concentração inibitória mínima, que varia de acordo com a espécie bacteriana em questão, na faixa de 0,2 a $100 \mu \mathrm{g} \mathrm{mL}^{-1}$ (Ruangpan \& Kitao, 1992; Lightner, 1996). A incorporação de OTC à ração para tratamento de camarões com bacterioses é bastante relatada (Mohney et al., 1997; Cruz-Lacierda et al., 2000; Barbieri Júnior \& Ostrensky Neto, 2002; Bray et al., 2006; Nogueira-Lima et al., 2006), e há variação da concentração de OTC na ração de acordo com a espécie e o tempo de medicação.

No Brasil, foram estabelecidas normas e implementados programas nacionais com o objetivo de fiscalizar e monitorar a utilização de substâncias danosas à saúde humana nos alimentos (Brasil, 2003, 2006, 2008). Devido à ausência de legislação reguladora para a utilização de OTC na aquicultura brasileira, são adotados regulamentos internacionais que estabelecem os limites máximos de resíduos (LMR). Um dos mais rigorosos critérios de avaliação de produtos alimentícios é estabelecido pelo mercado europeu, principal destino dos camarões produzidos no Brasil, que adota um LMR de $0,1 \mu \mathrm{g} \mathrm{g}^{-1}$ (European Medicines Agency, 1990).

Para o controle da qualidade dos alimentos, métodos de ensaios para a obtenção de resultados confiáveis e rastreáveis que utilizem técnicas analíticas reconhecidas e sejam validados segundo padrões estabelecidos por órgãos competentes são cada vez mais requeridos.

A cromatografia líquida de alta eficiência (CLAE) é uma técnica largamente utilizada para a determinação de OTC em músculo de camarões de várias espécies, entre elas Macrobrachium rosenbergii (Brillantes et al., 2001), Penaeus japonicus (Uno, 2004), Penaeus monodon (Sangrungruang et al., 2004; Reed et al., 2004, 2006; Uno et al., 2006) e Litopenaeus vannamei (Nogueira-Lima et al., 2006; Faroongsarng et al., 2007; Gomez-Jimenez et al., 2008). Nesse contexto, estudos científicos são essenciais para o estabelecimento de períodos de carência adequados à espécie animal e às condições ambientais em questão, bem como para a regulamentação de substâncias para uso veterinário na aquicultura no Brasil.

O objetivo deste trabalho foi validar um método para determinação de OTC em camarões por meio da técnica de CLAE com deteç̧ão por arranjos de diodos (DAD) e avaliar, utilizando o método validado, a depleção de resíduo de OTC na carapaça e no músculo de camarões submetidos a diferentes tratamentos com a droga.

\section{Material e Métodos}

Os solventes e reagentes utilizados nas análises cromatográficas foram de grau CLAE. A água utilizada no preparo das soluções foi ultrapura $(1,8 \mathrm{M} \Omega)$. Foram utilizados padrões de referência da United States Pharmacopeial Convention (USP, EUA) para o preparo das soluções padrão de OTC, na faixa de trabalho de 20 a $400 \mu \mathrm{g} \mathrm{mL} \mathrm{mL}^{-1}$, e de tetraciclina, esta última para padronização interna na concentração constante de $0,1 \mu \mathrm{g} \mathrm{mL}{ }^{-1}$. Para a realização dos testes de validação, foram utilizados camarões isentos de OTC, analisados em laboratório, e camarões adicionados de OTC in vitro, por meio da transferência de alíquotas de solução padrão concentrada. 
O método de análise de OTC utilizado foi elaborado com base em Nogueira-Lima et al. (2006), com modificações: na etapa de extração em fase líquida, o volume total do solvente para extração foi de $20 \mathrm{~mL}$ e a etapa de resfriamento e descanso no escuro foi eliminada; a etapa de limpeza em fase sólida utilizando cartuchos poliméricos foi incluída; nas condições cromatográficas, a fase móvel foi de 75:14:11 (v/v/v) de ácido oxálico $0,01 \mathrm{~mol} \mathrm{~L}^{-1}$, acetonitrila e metanol; o volume de injeção da amostra foi de $50 \mu \mathrm{L}$.

As amostras de camarão $(1 \mathrm{~kg})$ isentas de OTC utilizadas para a validação do método foram provenientes de fazendas comerciais do litoral Sul de Pernambuco. Depois de retirada a carapaça, o músculo foi homogeneizado em liquidificador industrial de alta velocidade (METVISA, Brasil). As amostras de músculo e de carapaça de camarão oriundas do experimento foram manualmente homogeneizadas em cadinhos de porcelana para avaliação das concentrações de OTC.

A extração em fase líquida foi iniciada a partir de $1 \mathrm{~g}$ de amostra homogeneizada com $10 \mathrm{~mL}$ de tampão Mcllvaine $0,01 \mathrm{~mol} \mathrm{~L}^{-1}$ de EDTA $\mathrm{pH} 4$ em ultrassom (VCX 130 Vibra Cell, EUA). A essa mistura foi adicionado $1 \mathrm{~mL}$ de ácido tricloroacético $24 \%(\mathrm{v} / \mathrm{v})$ para desproteinização. Após centrifugação (centrífuga Jouan B4i, França) a $9.500 \mathrm{rpm}$ por $5 \mathrm{~min}$, o sobrenadante foi recolhido e o material retido no fundo do tubo foi submetido a nova extração. Após união dos sobrenadantes, foram adicionados $2 \mathrm{~mL}$ de n-hexano com posterior centrifugação a $4.000 \mathrm{rpm}$ por $5 \mathrm{~min}$. A fase lipídica ou superior foi descartada e a fase aquosa foi aplicada em cartucho polimérico de $3 \mathrm{~mL}$ com $200 \mathrm{mg}$ de estireno-divinilbenzeno (Phenomenex, EUA) para limpeza em fase sólida. Após lavagem dos cartuchos para remoção dos interferentes, a eluição foi realizada com $3 \mathrm{~mL}$ de metanol. A evaporação do eluato (evaporador rotativo Büchi R-200, Itália) ocorreu a $40^{\circ} \mathrm{C}$ por $10 \mathrm{~min}$, e a reconstituição do resíduo seco foi realizada em $1 \mathrm{~mL}$ de ácido oxálico $0,01 \mathrm{~mol} \mathrm{~L}^{-1}$ com posterior agitação em vórtex (Phoenix AP 56, Brasil), por um minuto. $\mathrm{O}$ extrato final foi filtrado em membrana de acetato de celulose de $0,22 \mu \mathrm{m}$ acoplada a uma seringa de $1 \mathrm{~mL}$, e foi coletado para posterior análise em CLAE.

As análises de OTC foram realizadas em CLAE acoplado com DAD (Agilent Technologies série 1100, EUA) composto de bomba quaternária de alta pressão (G1311A), desgaseificador (G1322A), forno (G1316A), detector com arranjo de diodos (G1315A) e autoinjetor (G1313A). Para a separação dos componentes da amostra, foi utilizada uma coluna em C 18 (Phenomenex, 250x4 mm, $5 \mu \mathrm{m}$ ). Foram estabelecidos volume de injeção de $50 \mu \mathrm{L}$, detecção a $365 \mathrm{~nm}$ e fase móvel composta por ácido oxálico $0,01 \mathrm{~mol} \mathrm{~L}^{-1}$, acetonitrila e metanol $(75: 14: 11, \mathrm{v} / \mathrm{v} / \mathrm{v}) \mathrm{a}$ um fluxo de $1 \mathrm{~mL} \mathrm{~min}^{-1}$.

O método proposto para determinação de OTC em camarão foi validado segundo o guia do Instituto Nacional de Metrologia, Normalização e Qualidade Industrial (Inmetro, 2007), do qual constam orientações sobre validação de métodos de ensaios químicos. Foram estabelecidos: a seletividade do método, o tempo de retenção, a linearidade (coeficiente de correlação), a faixa de trabalho, a recuperação relativa (por padronização interna), os limites de detecção e quantificação do método (LDM e LQM, respectivamente) e a repetibilidade.

$\mathrm{O}$ experimento in vivo foi conduzido na Estação Experimental Professor Johei Koike da Universidade Federal Rural de Pernambuco (UFRPE), Recife, PE, no período de novembro de 2007 a janeiro de 2008. Camarões juvenis da espécie $L$. vannamei com $4,45 \pm 0,94 \mathrm{~g}$, provenientes de uma fazenda do litoral Norte do Estado de Pernambuco, foram aclimatados por 30 dias em tanques de fibra de vidro de $500 \mathrm{~L}$ contendo água marinha tratada (filtrada, clorada e declorada). Os animais foram distribuídos aleatoriamente em oito tanques na densidade de 28 camarões por tanque e cultivados em sistema fechado com aeração constante. A reposição da água foi realizada de acordo com a evaporação.

Os tratamentos, em duplicata, se diferenciaram pela quantidade de OTC administrada na ração no período de 14 dias. A adição de OTC na ração foi realizada de acordo com o procedimento utilizado por Brock \& Main (1994). As baixas concentrações de OTC definidas para os tratamentos visaram avaliar o limite de detecção encontrado para o método. Foram utilizadas as concentrações de 200,400 e $500 \mu \mathrm{g} \mathrm{g}^{-1}$, além do controle sem a droga (testemunha). A ração utilizada, com $35 \%$ de proteína bruta (Purina, Brasil) adicionada de oxitetraciclina comercial com $50 \%(\mathrm{~m} / \mathrm{m})$ de OTC base, foi fornecida à taxa de aproximadamente $4 \%$ da biomassa por dia, dividida em duas alimentações, às $8 \mathrm{~h}$ e às $16 \mathrm{~h}$. A ração adicionada de OTC a 200, $400 \mathrm{e}$ 
$500 \mu \mathrm{g} \mathrm{g}^{-1}$ foi mantida refrigerada, e a concentração de OTC fornecida para cada tratamento foi de aproximadamente 8,16 e $20 \mu \mathrm{g} \mathrm{g}^{-1}$ de biomassa de camarão por dia, respectivamente. Três camarões foram coletados de cada tanque no 1ㅇ, 5o, 10ㅇ, 13o, $16^{\circ}, 19^{\circ}$ e $22^{\circ}$ dia após o término do fornecimento do antibiótico. O músculo e a carapaça dos animais foram separados cuidadosamente, embalados com papel alumínio e congelados a $-20^{\circ} \mathrm{C}$ para avaliação do tempo de depleção da droga.

Amostras de água dos tanques e de hepatopâncreas dos animais foram coletadas para a realização de contagens de Vibrio spp. de acordo com o método citado por Silva et al. (1997), com o intuito de verificar a interferência do antibiótico na população dessas bactérias.

A temperatura e o oxigênio dissolvido (oxímetro YSI Incorporation 550A, EUA), a salinidade (refratômetro Atago S-10E, EUA) e o $\mathrm{pH}$ (medidor digital de $\mathrm{pH}$ Homis 1002PH, Brasil) da água dos tanques foram monitorados diariamente durante todo o cultivo.

Foi utilizado o teste $\mathrm{F}$ para analisar a homogeneidade dos dados quanto à variância. As médias foram comparadas pelo teste de Tukey, a 5\% de probabilidade. Foi utilizada regressão linear nos resultados obtidos nas análises de OTC na carapaça.

\section{Resultados e Discussão}

Os cromatogramas obtidos para a solução padrão a $0,1 \mu \mathrm{g} \mathrm{mL}^{-1}$, para o músculo do camarão fortificado a $0,1 \mu \mathrm{g} \mathrm{g}^{-1}$ e para o músculo de camarão isento de OTC, são apresentados na Figura 1. A Figura 2 mostra os cromatogramas da carapaça com OTC e da carapaça isenta de OTC. Nas condições cromatográficas utilizadas, foram obtidos o tempo de retenção de OTC de 6,9 min e o coeficiente de correlação linear de 0,9998 para OTC em solução, na faixa de trabalho de 0,02 a $0,4 \mu \mathrm{g} \mathrm{mL}^{-1}$. Para OTC no extrato da matriz na faixa de trabalho de 0,02 a $0,4 \mu \mathrm{g} \mathrm{g}^{-1}$, o coeficiente de correlação foi de 0,9997 , a recuperação relativa foi de $106,0 \pm 17,1 \%$, na concentração de fortificação de $0,1 \mu \mathrm{g} \mathrm{g}^{-1}$, a repetibilidade como coeficiente de variação foi de $16,1 \%$ e os LDM e LQM foram de 0,006 e $0,019 \mu \mathrm{g} \mathrm{g}^{-1}$, respectivamente. O método demonstrou ser seletivo, e não houve interferentes da matriz no tempo de retenção do analito (Figura 1).

O LDM e o LQM do método de Nogueira-Lima et al. (2006), com as modificações realizadas neste trabalho, foram inferiores aos do método original, estimados em $0,05 \mu \mathrm{g} \mathrm{g}^{-1}$. Esses resultados indicam que o método foi otimizado e que atende ao LMR de $0,1 \mu \mathrm{g} \mathrm{g}^{-1}$ para OTC de acordo com as diretrizes estabelecidas pela União Europeia (European Medicines Agency, 1990). O limite de detecção obtido no presente trabalho também foi inferior ao apresentado por vários autores que utilizaram a CLAE-DAD para a determinação de OTC, em várias espécies de camarão que variou de 0,008 a $0,5 \mu \mathrm{g} \mathrm{g}^{-1}$ (Uno, 2004; Reed et al., 2004, 2006; Uno et al., 2006; Faroongsarng et al., 2007; Gomez-Jimenez et al., 2008).

A recuperação relativa e o coeficiente de variação (CV) calculados para a concentração de $0,1 \mu \mathrm{g} \mathrm{g}^{-1}$ estão dentro da faixa de 70 a $110 \%$ para recuperação e CV máximo de $20 \%$ estabelecidos pelo Codex Alimentarius (2003). A recuperação obtida com as modificações realizadas
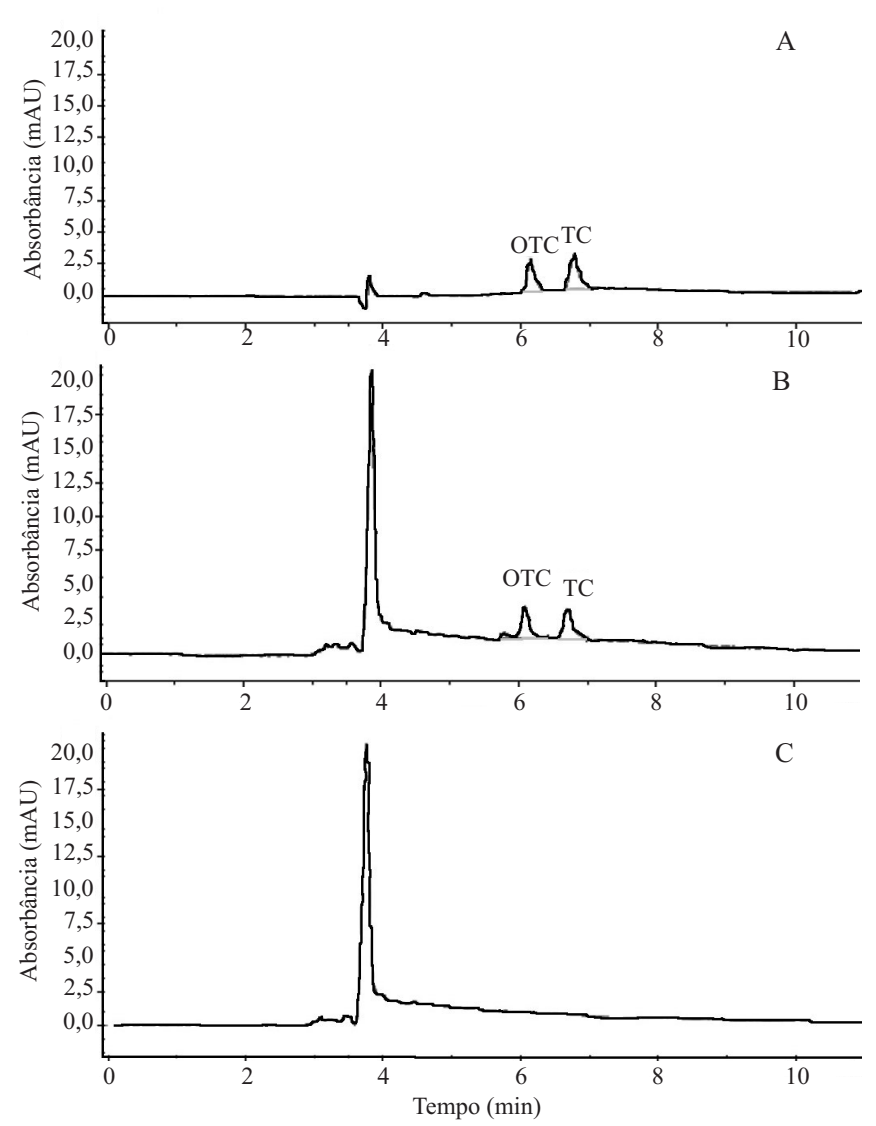

Figura 1. Cromatogramas para oxitetraciclina (OTC) e tetraciclina (TC): solução padrão de OTC e TC a $0,1 \mu \mathrm{g} \mathrm{mL} \mathrm{mL}^{-1}$ (A); extrato do músculo de camarão marinho (Litopenaeus vannamei) fortificado a $0,1 \mu \mathrm{g} \mathrm{g}^{-1}$ de OTC e TC (B); e extrato do músculo de camarão isento de OTC e TC (C). 
no método de Nogueira-Lima et al. (2006) foi maior que a definida no método original, de $81,68 \pm 1,54 \%$. Esses resultados possivelmente se devem à repetição da etapa de extração e à inclusão da etapa de limpeza em fase sólida, modificações que promoveram uma extração mais eficiente em comparação com a do método original.

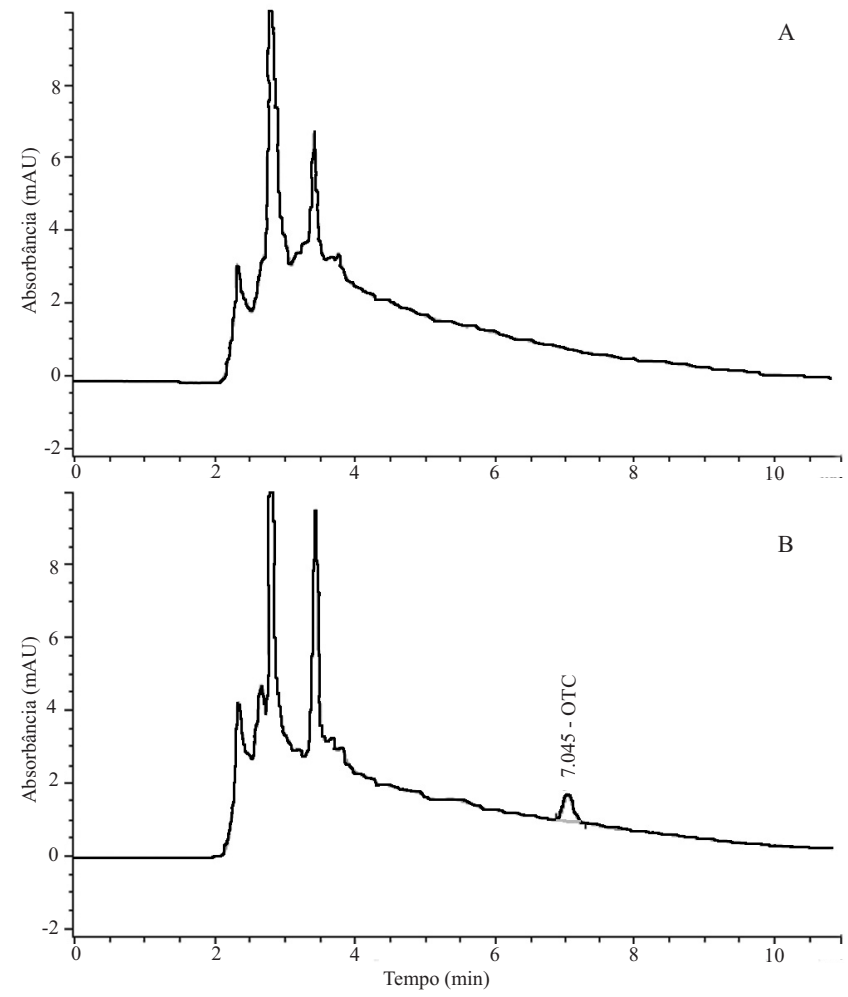

Figura 2. Cromatograma de amostra de carapaça de camarão marinho (Litopenaeus vannamei) isenta de oxitetraciclina (OTC), obtido no tratamento controle (A); cromatograma de amostra de carapaça de camarão com OTC, obtido no tratamento de $500 \mu \mathrm{g} \mathrm{g}^{-1}$ de OTC na ração (B).
Os coeficientes de correlação linear para OTC em solução e no extrato da matriz fortificado foram considerados satisfatórios pelo critério de aceitação de $r>0,90$, estabelecido pelo Inmetro (2007).

Lightner (1996) relata que, para o controle efetivo de vibrioses em camarões da espécie $P$. japonicus, foi necessário o fornecimento de OTC de 45 a $150 \mu \mathrm{g} \mathrm{g}^{-1}$ de biomassa de camarão. No presente trabalho, foram delineados tratamentos com baixas concentrações de OTC por biomassa, de 8,16 e $20 \mu \mathrm{g} \mathrm{g}^{-1}$, confirmadas pela análise das rações que apresentaram as concentrações de 200, 400 e $500 \mu \mathrm{g}$ OTC g ${ }^{-1}$. Essas baixas dosagens foram necessárias para comprovar, utilizando animais in vivo, que o limite de detecção do método obtido atende aos requisitos estabelecidos de quantificação.

Não houve diferença significativa entre as médias de concentração de resíduos de OTC nos músculos de camarão dos três tratamentos (Tabela 1). As concentrações no primeiro dia depois de cessada a administração da droga estavam abaixo do LMR de $0,1 \mu \mathrm{g} \mathrm{OTC} \mathrm{g}^{-1}$ (European Medicines Agency, 1990). Não foi detectado resíduo de OTC nos músculos, em todos os tratamentos, a partir do quinto dia após o término da medicação. Nas carapaças dos tratamentos de 400 e $500 \mu \mathrm{g} \mathrm{g}^{-1}$, o limite de detecção para OTC foi atingido no décimo dia após o término da dosagem de OTC na ração. Porém, no tratamento de $200 \mu \mathrm{g} \mathrm{g}^{-1}$, a depleção da droga foi verificada somente no $13^{\circ}$ dia após o término do fornecimento da medicação (Tabela 1, Figura 3). Apesar dos diferentes tempos de depleção constatados na carapaça, as médias dos resultados entre os tratamentos não diferiram estatisticamente. As concentrações de OTC na carapaça dos camarões de todos os tratamentos permaneceram abaixo do LMR no quinto dia após a suspensão do fornecimento da droga.

Tabela 1. Tempo de depleção residual de oxitetraciclina (OTC) na carapaça e músculo de camarão marinho (Litopenaeus vannamei) nas diferentes concentrações de OTC adicionadas à ração ${ }^{(1)}$.

\begin{tabular}{|c|c|c|c|c|c|c|}
\hline \multirow{3}{*}{$\begin{array}{l}\text { Dia após a } \\
\text { medicação }\end{array}$} & \multicolumn{6}{|c|}{ Tratamentos $\left(\mu \mathrm{g} \mathrm{g}^{-1}\right)$} \\
\hline & \multicolumn{2}{|c|}{200} & \multicolumn{2}{|c|}{400} & \multicolumn{2}{|c|}{500} \\
\hline & Músculo & Carapaça & Músculo & Carapaça & Músculo & Carapaça \\
\hline $1^{\underline{0}}$ & $0,028 \pm 0,006$ & $0,13 \pm 0,06$ & $0,037 \pm 0,007$ & $0,15 \pm 0,09$ & $0,014 \pm 0,004$ & $0,051 \pm 0,006$ \\
\hline $5^{-0}$ & $-(2)$ & $0,049 \pm 0,001$ & - & $0,045 \pm 0,001$ & - & $0,017 \pm 0,007$ \\
\hline $10^{\underline{0}}$ & - & $0,038 \pm 0,007$ & - & - & - & - \\
\hline $13^{\circ}$ & - & - & - & - & - & - \\
\hline
\end{tabular}

${ }^{(1)}$ Médias \pm desvio-padrão. ${ }^{(2)}$ Valores não detectáveis. 
As médias e os intervalos de confiança para temperatura, salinidade, $\mathrm{pH}$ e oxigênio dissolvido foram de $30,54 \pm 2,78^{\circ} \mathrm{C}, 30,18 \pm 0,61 \mathrm{~g} \mathrm{~L}^{-1}, 8,36 \pm 0,34 \mathrm{e}$ $5,75 \pm 0,82 \mathrm{mg} \mathrm{L}^{-1}$, respectivamente. As médias entre os tratamentos, para todos os parâmetros avaliados, não apresentaram diferenças significativas. Também não houve diferença significativa entre os tratamentos para as contagens de Vibrio spp. na água e no hepatopâncreas, embora valores máximos de contagem tenham sido observados neste último.

Os resultados bacteriológicos obtidos são pertinentes para o pouco ou nulo efeito da droga devido às baixas concentrações estabelecidas, pois não foi verificada diferença estatística entre os tratamentos. Não existiu relação entre o número de bactérias das amostras de água e hepatopâncreas e a concentração de OTC no músculo e na carapaça. No entanto, o número de víbrios no hepatopâncreas foi, em média, superior ao verificado na água.

$\mathrm{O}$ uso de antibióticos na aquicultura deve ser devidamente controlado, pois a desinformação e a negligência podem originar o uso tanto de subdosagens quanto de superdosagens. Ambas as situações podem induzir a resistência bacteriana (Mendes et al., 2004). A administração de subdosagens pode levar à rápida propagação de genes com resistência a múltiplos antibióticos (Moriarty, 2003), com possibilidade de transferência de plasmídios de resistência entre espécies provenientes do ambiente aquático e o homem (Rhodes et al., 2000). Vários autores afirmaram a necessidade de controlar a utilização de fármacos, aditivos e fertilizantes na aquicultura, pois o descontrole pode afetar os ecossistemas marinhos e costeiros e também a saúde humana (Holmström et al., 2003; Lalumera

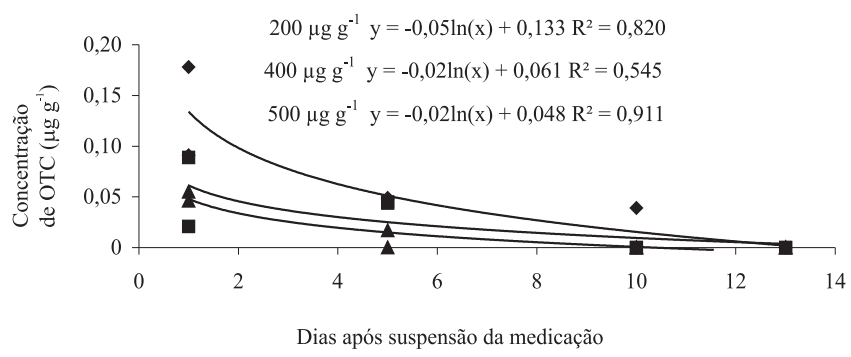

Figura 3. Concentrações de resíduo de oxitetraciclina (OTC) na carapaça de camarão marinho (Litopenaeus vannamei) após a suspensão da droga, nas diferentes concentrações de OTC adicionadas à ração. Foram utilizadas as médias de duas injeções no equipamento para duplicatas de cada tratamento. et al., 2004; Le et al., 2005; Christensen et al., 2006; Lyle-fritch et al., 2006).

Para o controle do uso de drogas, é necessário conhecer o tempo de depleção. Verificou-se, no presente trabalho, que o tempo de depleção de OTC foi menor no músculo (cinco dias) que na carapaça (13 dias), em todos os tratamentos. Esse menor tempo de depleção da droga pode estar associado à baixa concentração de OTC administrada na ração, pois Nogueira-Lima et al. (2006), ao submeterem camarões cultivados em tanques a um tratamento com $4.500 \mu \mathrm{g} \mathrm{g}^{-1}$ de OTC na ração por 14 dias, observaram que a concentração de OTC no músculo diminuiu para $0,05 \mu \mathrm{g} \mathrm{g}^{-1}$ apenas no $25^{\mathrm{o}}$ dia após a suspensão do tratamento. Gómez-Jimenez et al. (2008) verificaram que foi necessário um período de dez dias após o término do tratamento com OTC a $5.000 \mu \mathrm{g} \mathrm{g}^{-1}$ na ração por 14 dias para que a concentração de OTC no músculo de L. vannamei diminuísse para $0,01 \mu \mathrm{g} \mathrm{g}^{-1}$.

Segundo Uno (2004), a carapaça dos camarões é uma estrutura importante na distribuição de OTC. Bray et al. (2006) utilizaram concentrações entre 4.500 e $22.500 \mu \mathrm{g} \mathrm{g}^{-1}$ dessa droga na ração, e observaram que a interrupção do crescimento do exoesqueleto poderia estar associada à formação primária de cálcio e magnésio. Arias et al. (2007) citam que a OTC apresenta a propriedade de formar complexos metálicos com cátions divalentes por ser uma molécula receptora de elétrons. A carapaça dos camarões é formada por 15 a $20 \%$ de quitina, 25 a $40 \%$ de proteínas e 40 a $55 \%$ de sais inorgânicos, principalmente carbonato de cálcio, um íon divalente (Marthur \& Narang, 1990). Os grupos acetamidas da quitina se ligam aos cátions metálicos (sais) e formam a carapaça.

Os processos que envolvem aumento de temperatura, como o cozimento, diminuem em apenas $20 \%$ as concentrações de OTC em amostras de carapaça. Em amostras cruas, a OTC é acumulada e retida formando complexos metálicos, o que dificulta a remoção da droga de estruturas dessa natureza. No entanto, em músculo, até $80 \%$ da OTC é eliminada quando submetida ao mesmo procedimento (Uno et al., 2006).

Diante do exposto, é recomendável avaliar a concentração de OTC no camarão inteiro e não somente no músculo, contrariamente à determinação de órgãos regulamentadores como a Comunidade Europeia e a Food and Drug Administration (FDA), 
que estabelecem os limites de 0,1 e $0,2 \mu \mathrm{g} \mathrm{g}^{-1}$ para OTC em tecidos animais, respectivamente (European Medicines Agency, 1990; Codex Alimentarius, 2006).

\section{Conclusões}

1. O método validado atende ao uso pretendido, pois apresenta um dos mais baixos limites de detecção definidos para métodos que empregam a CLAE-DAD.

2. Os coeficientes de correlação para oxitetraciclina em solução e no extrato da matriz fortificado, faixa de trabalho, recuperação relativa e repetitividade são satisfatórios, de acordo com as normas vigentes.

3. O acúmulo de resíduo de oxitetraciclina, quando administrada na ração, é maior na carapaça que no músculo de camarão marinho Litopenaeus vannamei, sobretudo devido à diferença na composição estrutural das partes da matriz.

\section{Agradecimentos}

Ao Conselho Nacional de Desenvolvimento Científico e Tecnológico e à Financiadora de Estudos e Projetos, pelo apoio financeiro; ao Instituto de Tecnologia de Pernambuco, pela oportunidade de desenvolver este trabalho no Laboratório de Contaminantes Químicos e Biológicos; ao Engenheiro de Pesca Ugo Lima e à Médica Veterinária Suely Santos Bezerra, pelo apoio técnico.

\section{Referências}

ARIAS, M.; GARCIA-FALCÓN, M.S.; GARCIA-RIO, L.; MEJUTO, J.C.; RIAL-OTERO, R.; SIMAL-GÁNDARA, J. Binding constants of oxytetracycline to animal feed divalent cations. Journal of Food Engineering, v.78, p.69-73, 2007.

BARBIERI JÚNIOR, R.C.; OSTRENSKY NETO, A. Camarões marinhos: engorda. Viçosa: Aprenda Fácil, 2002. 370p.

BRASIL. Instrução normativa no 10 , de 14 de abril de 2008 . Aprova os programas de controle de resíduos e contaminantes em carnes (bovina, aves, suína e eqüina), leite, mel, ovos e pescado do exercício de 2008. Diário Oficial [da] República Federativa do Brasil, 17 abr. 2008. Seção 1, p.29-34. Disponível em: <http:// extranet.agricultura.gov.br/sislegis-consulta/consultarLegislacao.d o? operacao=visualizar\&id=18586>. Acesso em: 20 fev. 2009.

BRASIL. Ministério da Agricultura,Agropecuária e Abastecimento. Plataforma tecnológica do camarão marinho cultivado. Brasília: MAPA, 2001. 276p.

BRASIL. Portaria no 50, de 20 de fevereiro de 2006. Aprova os programas de controle de resíduos em carne (bovina, aves, suína e eqüina), leite, mel, ovos e pescado do exercício de 2006. Diário Oficial [da] República Federativa do Brasil, 03 mar. 2006. Seção 1, p.15-25.
Disponível em: <http://extranet.agricultura.gov.br/sislegis-consulta/ consultarLegislacao.do?operacao $=$ visualizar\&id $=16693>$. Acesso em: 20 fev. 2009.

BRASIL. Resolução RDC no 253, de 16 de setembro de 2003. Cria programa de análise de resíduos de medicamentos veterinários em alimentos de origem animal - PAMVet. Diário Oficial [da] República Federativa do Brasil, 18 set. 2003. Disponível em: $\quad<$ http://e-legis.anvisa.gov.br/leisref/public/showAct. php?id=8128>. Acesso em: 20 fev. 2009.

BRAY, W.A.; WILLIAMS, R.R.; LIGHTNER, D.V.; LAWRENCE, A.L. Growth, survival and histological responses of the marine shrimp, Litopenaeus vannamei, to three dosage levels of oxytetracycline. Aquaculture, v.258, p.97-108, 2006.

BRILLANTES, S.; TANASOMWANG, V.; THONGROD, S.; DACHANANTAWITAYA, N. Oxytetracycline residues in giant freshwater prawn (Macrobrachium rosenbergii). Journal of Agricultural and Food Chemistry, v.49, p.4995-4999, 2001.

BROCK, J.A.; MAIN, K.L. A guide to the common problems and diseases of cultured Penaeus vannamei. Baton Rouge: Oceanic Institute, 1994. 241p.

BRUNTON, L. Goodman and Gilmans the pharmacological basis of therapeutics. $11^{\text {th }}$ ed. New York: McGraw-Hill, 2006. 1984p.

CHRISTENSEN, A.M.; INGERSLEV, F.; BAUN, A. Ecotoxicity of mixtures of antibiotics used in aquacultures. Environmental Toxicology and Chemistry, v.25, p.2208-2215, 2006.

CODEX ALIMENTARIUS. Límites máximos de residuos para medicamentos en los alimentos. Roma: Codex Alimentarius, 2006. 32p.

CODEX ALIMENTARIUS. Revisión de los criterios basados en el rendimientos de los métodos de análisis para los residuos de medicamentos veterinarios en los alimentos. Roma: Codex Alimentarius, 2003. 23p.

CRUZ-LACIERDA, E.R.; DE LA PEÑNA, L.; LUMANLAN-MAYO, S. The use of chemicals in aquaculture in the Philippines. In: ARTHUR, J.R.; LAVILLA-PITOGO, C.R.; SUBASINGHE, R.P. (Ed.). Use of chemicals in aquaculture in Asia. Iloilo: Southeast Asian Fisheries Development Center, 2000. p.155-184.

EUROPEAN MEDICINES AGENCY. Council regulation (EEC) no 2377/90, of 26 June 1990. Laying down a Community procedure for the establishment of maximum residue limits of veterinary medicinal products in foodstuffs of animal origin. Official Journal of the European Communities, 18 Aug. 1990. Disponível em: $<$ http://ec.europa.eu/enterprise/pharmaceuticals/eudralex/vol5_ en.htm>. Acesso em: 20 fev. 2009.

FAROONGSARNG, D.; CHANDUMPAI, A.; CHIAYVAREESAJJA, S.; THEAPPARAT, Y. Bioavailability and absorption analysis of oxytetracycline orally administered to the standardized moulting farmed Pacific white shrimps (Penaeus vannamei). Aquaculture, v.269, p.89-97, 2007.

FOOD AND AGRICULTURE ORGANIZATION OF THE UNITED NATIONS. Fisheries and aquaculture department: statistics and information. Rome: FAO, 2008. Disponível em: <www.fao.org/fishery>. Acesso em: 20 jan. 2009. 
GOMEZ-JIMENEZ, S.; ESPINOSA-PLASCENCIA, A.; VALENZUELA-VILLA， F.; BERMUDEZ-ALMADA， M.C. Oxytetracycline (OTC) accumulation and elimination in hemolymph, muscle and hepatopancreas of white shrimp Litopenaeus vannamei following an OTC-feed therapeutic treatment. Aquaculture, v.274, p.24-29, 2008.

HOLMSTRÖM, K.; GRÄSLUND, S.; WAHLSTRÖM, A.; POUNGSHOMPOO, S.; BENGTSSON, E.; KAUTSKY, N. Antibiotic use in shrimp farming and implications for environmental impacts and human health. International Journal of Food Science and Technology, v.38, p.255-266, 2003.

INMETRO. Orientações sobre validação de métodos. 2.ed. rev. Brasília: Inmetro, 2007. 25p.

LALUMERA, G.M.; CALAMARI, D.; GALLI, P.; CASTIGLIONI, S.; CROSA, G.; FANELLI, R. Preliminary investigation on the environmental occurrence and effects of antibiotics used in aquaculture in Italy. Chemosphere, v.54, p.661-668, 2004.

LE, T.X.; MUNEKAGE, Y.; KATO, S.I. Antibiotic resistance in bacteria from shrimp farming in mangrove areas. Science of the Total Environment, v.349, p.95-105, 2005.

LIGHTNER, D.V. A handbook of shrimp pathology and diagnostic procedures for diseases of cultured penaeid shrimp. Baton Rouge: World Aquaculture Society, 1996. 304p.

LYLE-FRITCH, L.P.; ROMERO-BELTRÁN, E.; PÁEZ-OSUNA, F. A survey on use of the chemical and biological products for shrimp farming in Sinaloa (NW Mexico). Aquacultural Engineering, V.35, p.135-146, 2006.

MARTHUR, N.K.; NARANG, C.K. Chitin and chitosan, versatile polysaccharides from marine animals. Journal of Chemical Education, v.67, p.938-942, 1990.

MENDES, E.S.; ALVES, C.A.B.; BEZERRA, S.S.; MENDES, P.P.; SANTOS, F.L. Sensibilidade in vitro à enrofloxacina e oxitetraciclina de víbrios isolados na larvicultura de camarão marinho (Litopenaeus vannamei). Ciência Veterinária nos Trópicos, v.7, p.90-97, 2004.

MOHNEY, L.L.; WILLIAMS, R.R.; BELL, T.A.; LIGHTNER, D.V. Residues of oxytetracycline in cultured juvenile blue shrimp, Penaeus stylirostris (Crustacea: Decapod), fed medicated feed for 14 days. Aquaculture, v.149, p.193-202, 1997.
MORIARTY, D.J.W. Os perigos do uso de antibióticos na aquacultura. 2003. Disponível em: <http://www.aqualider.com.br/ article.php?recid=88>. Acesso em: 20 jan. 2009.

NOGUEIRA-LIMA, A.C.; GESTEIRA, T.C.V.; MAFEZOLI, J. Oxytetracycline residues in cultivated marine shrimp (Litopenaeus vannamei Boone, 1931) (Crustacea, Decapoda) submitted to antibiotic treatment. Aquaculture, v.254, p.748-757, 2006.

OKA, H.; ITO, Y.; MATSUMOTO, H. Chromatographic analysis of tetracycline antibiotics in foods: review. Journal of Chromatography A, v.882, p.109-133, 2000.

REED, L.A.; SIEWICKI, T.C.; SHAH, J.C. Pharmacokinetics of oxytetracycline in the white shrimp, Litopenaeus setiferus. Aquaculture, v.232, p.11-28, 2004.

REED, L.A., SIEWICKI, T.C., SHAH, J.C. The biopharmaceutics and oral bioavailability of two forms of oxytetracycline to the white shrimp, Litopenaeus setiferus. Aquaculture, v.258, p.42-54, 2006.

RHODES, G.; HUYS, G.; SWINGS, J. Distribution of oxytetracycline resistance plasmids between aeromonads in hospital and aquaculture environments: implications of Tn1721 in dissemination of the tetracycline resistance determinant Tet A. Applied and Environmental Microbiology, v.66, p.3883-3890, 2000.

RUANGPAN, L.; KITAO, T. Minimal inhibitory concentration of 19 chemothertapeutants against Vibrio bacteria of shrimp, Penaeues monodon. In: SYMPOSIUM ON DISEASES IN ASIAN AQUACULTURE, 1., 1990, Bali. Proceedings. Manila: Asian Fisheries Society, 1992.

SANGRUNGRUANG， K.; CHOTCHUANG, A.; UENO, R. Comparative pharmacokinetics and bioavailability of oxytetracycline in giant tiger prawn. Fisheries Science, n.70, p.467-472, 2004.

SILVA, N. da; JUNQUEIRA, V.C.A.; SILVEIRA, N.F. de A. Manual de métodos de análise microbiológica de alimentos. São Paulo: Varela, 1997.230p.

UNO, K. Pharmacokinetics of oxolinic acid and oxytetracycline in Kuruma shrimp, Penaeus japonicus. Aquaculture, v.230, p.1-11, 2004.

UNO, K.; AOKI, T.; KLEECHAYA, W.; TANASOMWANG, V.; RUANGPAN, L. Pharmacokinetics of oxytetracycline in black tiger shrimp, Penaeus monodon, and the effect of cooking on the residues. Aquaculture, v.254, p.24-31, 2006.

Recebido em 28 de fevereiro de 2009 e aprovado em 17 de junho de 2009 